\title{
ORION, a new method for root cause analysis of blood and body fluid exposures
}

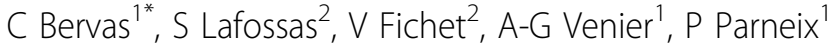 \\ From 3rd International Conference on Prevention and Infection Control (ICPIC 2015) \\ Geneva, Switzerland. 16-19 June 2015
}

\section{Introduction}

Blood and Body Fluid Exposures (BFFEs) involve a complex sequence of events combining technical, human and organizational factors. Performing root cause analysis (RCA) of these events is promoted to improve safety. We conducted a RCA of a BBFE in a radiology unit using a recently developed French method called Orion.

\section{Objectives}

The objective was to identify how the BBFE had happened and to implement actions to prevent its reoccurrence.

\section{Methods}

The starting point of the RCA was the report of a BBFE by a radiologist to occupational medicine. BBFE occurred during a non scheduled breast biopsy. Analysis was conducted in collaboration with occupational medicine and the Southwestern Centre for Healthcare Associated Infection Control. ORION comprises six steps: collecting data; rebuilding the chronology; identifying gaps; identifying contributing and influential factors; proposing actions to implement; writing the analysis report.

\section{Results}

The detailed chronology of events before, during and after the BBFE identified many gaps. The main influential factor was a sub-optimal organization during the breast biopsy: no protocol, inadequate room and time slot. Three corrective measures were retained: providing adequate safety container closer to the care procedure; providing adequate medical device to drag the carrot, reorganizing the care with an additionnal microbiopsy session close to RMI session.

${ }^{1}$ CCLIN Sud-Ouest, France

Full list of author information is available at the end of the article

\section{Conclusion}

This first use of the ORION method to analyse a BBFE proved successful. This method seems quasi-intuitive and easier to conduct than previously described methods because it relies on a detailed chronology. It allows the implementation of BBFEs preventive measures and promotes collaborative teamwork.

\section{Disclosure of interest}

None declared.

Authors' details

${ }^{1}$ CCLIN Sud-Ouest, France. ${ }^{2}$ Centre Hospitalier de Rochefort, France.

Published: 16 June 2015

doi:10.1186/2047-2994-4-S1-P266

Cite this article as: Bervas et al:: ORION, a new method for root cause

analysis of blood and body fluid exposures. Antimicrobial Resistance and Infection Control 2015 4(Suppl 1):P266.
Submit your next manuscript to BioMed Central and take full advantage of:

- Convenient online submission

- Thorough peer review

- No space constraints or color figure charges

- Immediate publication on acceptance

- Inclusion in PubMed, CAS, Scopus and Google Scholar

- Research which is freely available for redistribution 